\title{
DETERMINATION OF DEPENDENCE OF WOOD BIOMASS DISINTEGRATION PARAMETERS ON WATER CONTENT
}

Jiří SOUČEK, Research Institute of Agricultural Engineering, p. r. i., Drnovská 507, 161 01, Prague, Czech Republic, jiri.soucek@vuzt.cz (corespoundin author)

Algirdas JASINSKAS, Institute of Agricultural Engineering and Safety, Faculty of Agricultural Engineering, Aleksandras Stulginskis University, Kaunas-Akademija, Studentu str. 15A, LT-53361 Kaunas distr., Lithuania, algirdas.jasinskas@asu.lt

Mechanical properties of wood are an important aspect in its processing. Wood is traditionally used for construction and technical purposes. Recently, its importance has grown in energy use. For energy use, it is necessary to modify the wood dimensionally into the desired shape. Therefore, the disintegration is an important operation in wood processing. Its difficulty depends on the properties of the wood.

The authors have determined the parameters of energy-using wood species on a water content in the range of 0-50\%. The observed properties were wood shear stress. With decreasing water content, the shear stress of wood decreases. The shear strength limit of poplar wood increased from 22.3 MPa to 30.2 MPa. Poplar samples had a higher shear strength than willow samples.

Keywords: renewable energy, energy biomass, shear stress, shear strength, chipping, disintegration, poplar, wilow, wood properties

\section{INTRODUCTION}

The development of renewable energy sources is primarily focused on the use of water, sun, wind and plant biomass energy. From the economic and environmental point of view, the use of plant biomass appears to be the most efficient in European conditions. For direct combustion the wood is, and will be probably in the future, the most widely used raw material. However, it is necessary to modify the wood before its own energy use, especially dimensionally The technological operations for dimensioning are based on disintegration of wood with the use of crushers and chippers. About (Souček et al, 2008) the efficiency of processing depends on good choice of equipment used and its incorporation into the technological process of processing. The suitable choice of equipment depends on mechanical properties of raw materials, which are significantly influenced by instantaneous water content.

Measurement of mechanical properties of wood in relation to water content was determined in (Bachtiar et al, 2017). The work is aimed at Young's moduli, Poisson's ratios and determination of shear moduli of Chinese fir wood. The similar measurements with eucalyptus wood were carried out in (Lahr et al, 2017). Emphasis was placed on the determination of tensile strength. However, the predominant type of stress during the tree species disintegration by means of chipping is a stress. The measurement of shear stress limits was carried out for the purpose of possibility of laboratory specification of parameter changes during the tree chipping depending on the entire water content. The shear stress is about (Souček et al, 2003) one of the main indicators of wood species properties in process of disintegrations energy consumption.

From the available methods of determination of shear stress published in scientific literature there wasn't found any methodically described measurement procedure meeting the requirements, which are necessary for stress simulation during the chipping. The available methods go out from the standard (ČSN 49 0118), eventually from the standard (ČSN 49 0119). Measurement by means of special device with use of compressive strength (Longui et al, 2017). In methodically way the solutions are aimed at assessment of material for the purposes of building industry, not for the purposes of disintegration. From these reasons there was created the proper methodical process, which served to the determination of necessary values. The obtained results have been compared to the data in scientific literature. The values of shear strength limit of selected wood kinds according to the scientific literature (Peschel, 2002), Sobotáles nakladatelství) is mentioned in the table 1.

Table 1: Shear stress limit of selected wood

\begin{tabular}{|l|l|l|l|}
\hline \multirow{2}{*}{$\begin{array}{l}\text { Kind } \\
\text { of wood }\end{array}$} & \multicolumn{3}{|l|}{ Shear stress limit $(\mathrm{MPa})-$ Radial direction of stress } \\
\cline { 2 - 4 } & Minimum value & Maximum value & Mean value (for 12 - 17 \% of water content) \\
\hline poplar & 20.5 & 34.2 & 31.1 \\
\hline spruce & 25.5 & 44.0 & 31.8 \\
\hline beech & 41.2 & 65.1 & 52.3 \\
\hline
\end{tabular}

Copyright (C) 2017 The Authors. Published by Aleksandras Stulginskis University. This is an open-access article distributed under the terms of the Creative Commons Attribution License (CC-BY 4.0), which permits unrestricted use, distribution, and reproduction in any medium, provided the original author and source are credited. 


\section{RESEARCH METHODS}

The aim of the solution was to determine the dependence of the shear stress limits of wood biomass on the water content. Measured materials were samples of willow and poplar. Wood samples from tree species were taken from experimental energy plantations of the VÚZT - Research Institute of Agricultural Engineering.

These samples were taken from as small rollers cut from the entire cross section of the branches. When sampling, the emphasis was placed on small number of buds, knots or other defects. The diameter of the samples ranged from 5 to $20 \mathrm{~mm}$ and the length was $120 \mathrm{~mm}$. The collected samples were placed into a closed plastic packaging. Such treated samples were transported and stored in refrigerator for necessary period at temperature of $8^{\circ} \mathrm{C}$.

Before the experiments the samples were placed into a drying oven and heated to the temperature of $105^{\circ} \mathrm{C}$. In fifteen minutes intervals a predetermined number of samples (minimum 3) was removed from the drying oven. These samples were tested. A standard was determined and placed between the samples and this standard was clearly marked before the beginn of measurements. Each time when the samples were removed from the drying oven, the instantaneous weight of this standard was determined. Laboratory scales with a weighing accuracy $\pm 0.01 \mathrm{~g}$ were used to determine the weight. The measurement continued in quarter - hour intervals up to a constant weight (complete drying) of the standard.

The shear stress limit of prepared samples was determined by a static test on mechanical testing machine.

For the purposes of measurement, it was produced a adapter (jig) for measurement of shear stress limit (Fig.1). Construction of this device was designed with aim to simulate objectively the way of stress of wood biomass in process of disintegration by means of knife chipper.

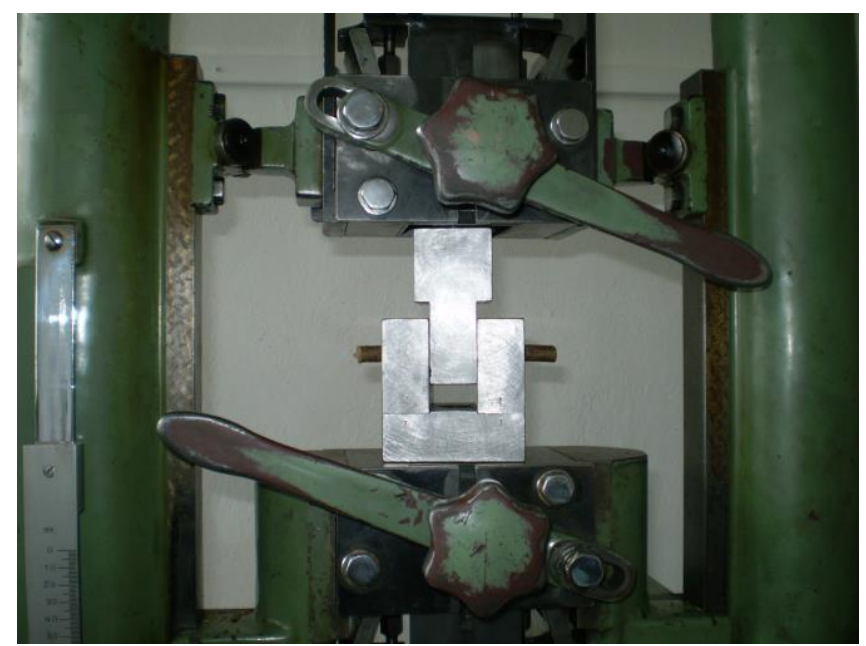

Figure 1. Adapter (jig) for measurement of shear stress limit

This device was manufactured from the tool steel. It is equipped by fittings, which enable its insertion into gripping jaws. Tested sample is stressed by means of this device in two parallel planes. The advantage of this device is, that can ensure the direction of stress and reduction of probability, that the measurement results will be influenced by defects of wood in the point of stress. This device is primarily destined for measurement of shear strength limit in transversal plane.

Before every realization of strength test there was determined the diameter of a sample by means of slide calliper. The calculation of resulting values was carried out according to the principle defined in the standard ČSN 490118 , with the difference, that measured samples had in shear plane a circular section and a sample was stressed in two planes.

Resulting relation for determination of shear strength limit by means of a adapter (jig) is:

$$
\tau_{s m}=\frac{F_{\max }}{\frac{\pi \cdot D^{2}}{2}}
$$

where: $F_{\text {max }}$ is maximum strength $(\mathrm{N}), D$ is diameter of a sample $(\mathrm{mm})$.

The speed of advance during the stress was $10 \mathrm{~mm} \cdot \mathrm{min}^{-1}$.

The measured material was poplar and willow.

All determined values were recorded and processed into tables and graphs in the MS EXCEL programme.

\section{RESULTS}

The results of realized experiments were statistically evaluated and processed into the graphs. The course of shear stress limit in dependence on all water content is shown in graphs on the Fig. 2 and Fig. 3. 


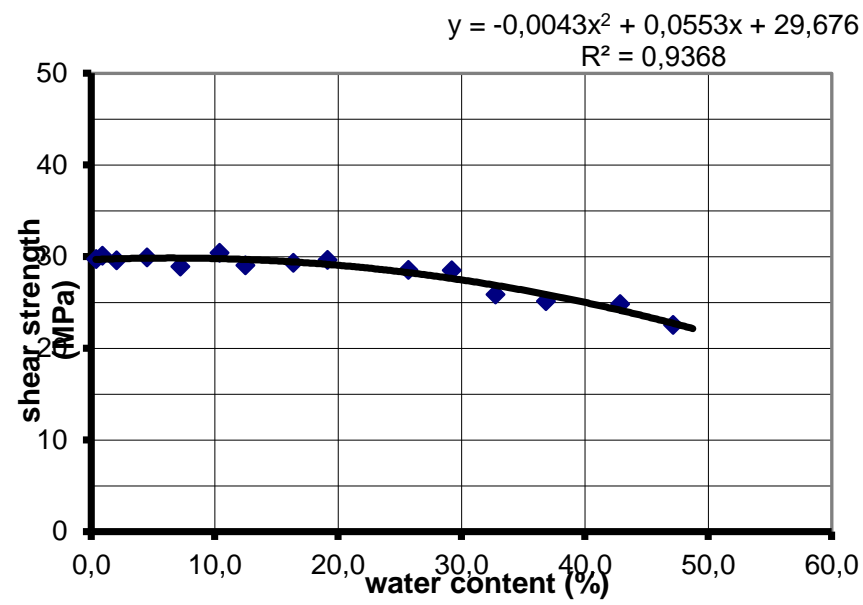

Figure 2. Course of shear strength limit in dependence on all water content - poplar

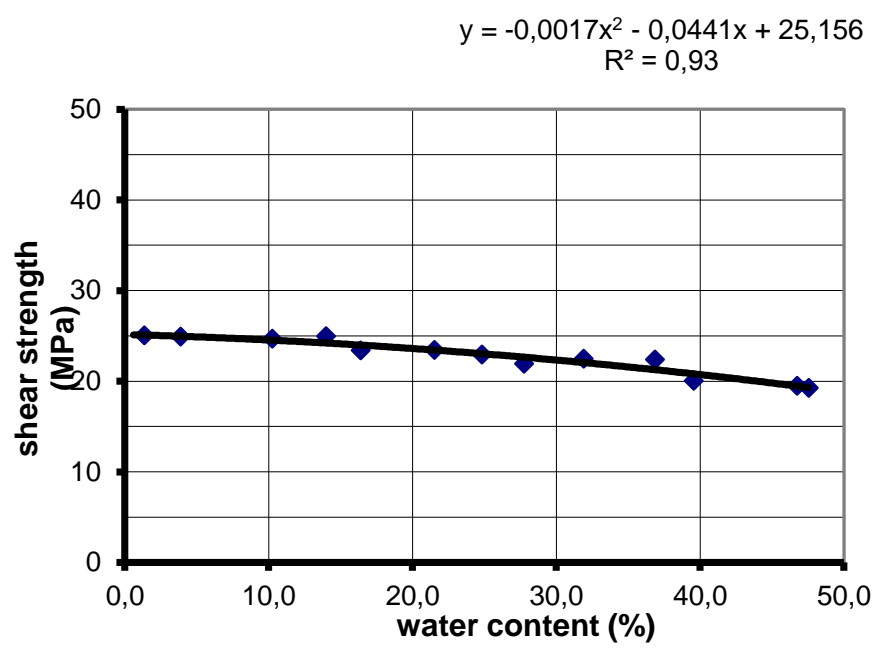

Figure 3. Course of shear strength limit in dependence on all water content - willow

\section{CONCLUSIONS AND DISCUSSION}

From the realized experiments results, that with decreasing water content in wood its shear strength is increasing. Poplar samples had a higher shear strength than willow samples.

When drying the poplar from $47.1 \%$ to $0 \%$ of all water content, the shear strength limit increased from $22.3 \mathrm{MPa}$ to $30.2 \mathrm{MPa}$, which makes $35.4 \%$.

The samples of willow were dried from all water content $47.5 \%$ also to $0 \%$. Shear strength limit increased in the course of drying process, from 19.5 MPa to $25.0 \mathrm{MPa}$. It means by $28.2 \%$.

These data, in spite of the use of different methods of measurement, correspond to the values obtained by the following authors (Longui et al, 2017).

Scientific literature (Peschel, 2002), mentions mean value of coefficient of variation for the shear stress limit \pm $14 \%$ from mean value. Furthermore, the authors draw attention to the fact, that this coefficient can be even higher depending on the kind of wood.

The values determined by impact test correspond to the values mentioned in wood handbook. The values gained in (Sinha et al, 2012) are higher, which it is caused by measurement of strength of other bonds (parallel to wood layers), which don't correspond to the direction of stress during the disintegration.

The used methods of measurement enable to test the samples at wider scale of water content, than (Lahr et al, 2017) or (Mirzaei, 2015). The advantage is in possibility of more accurate determination of course of variables. From the viewpoint of design of appropriate disintegration device, the knowledge of course of monitored variables is more important, than knowledge of discrete values.

From the course of determined values it is obvious, that the samples had lower strength limit at high water content. It is also one of the reasons, why it is more purposeful to use a chipper at disintegration of wet wood.

The difference in maximum value for poplar between measured value and value, which is mentioned in the table, is caused by use of various poplar clones. The important role can be also played by speed of advance.

Determination of shear strength is important from the point of view of designing machines and equipment that are used to disintegrate material for energy and material use. Mass disintegration operations are used during harvesting and further processing (production of pellets, briquettes, MDF boards, etc.). 
An important point is the design and practical verification of the method of determining the shear strength for different water content. The method makes it possible to optimize the technological processes of woodworking in terms of energy consumption reduction.

Another example is the processing of wood mass and biodegradable waste for the production of compost. Highquality woodworking with low energy consumption is a significant asset for the composting process. Choosing the right disintegration device in the composting line is important both technologically and economically.

The amount of wood to be processed is growing. The reason is to increase the capacity of the equipment for energy use and biofuel production. The second reason is to increase the share of selected biowaste. Wood is a substantial part of it. Higher efficiency and cost-effectiveness of the technology for its processing therefore becomes socially significant.

\section{ACKNOWLEDGMENT}

This proceeding originated within the project of long time development of Research Institute of Agricultural Engineering p.r.i. no. RO0617 and project no. QJ1510345 NAZV fo Ministery of Agriculture of the Czech Republic.

\section{REFERENCES}

1. ČSN 490118 , Shear strength limits in the fiber direction,

2. ČSN 49 0119, WOOD - Method of splitability detection.

3. Jiang, J., Bachtiar, E. V., Lu, J., Niemz, P. 2017. Moisture-dependent orthotropic elasticity and strength properties of Chinese fir wood. European Journal of Wood and Wood Products, Vol. 75, Iss. 6, 927-938. https://doi.org/10.1007/s00107-017-1166-y

4. Lahr, F. A. R., Christoforo, A. L. 2017. PHYSICAL-MECHANICAL CHARACTERIZATION OF Eucalyptus urophylla WOOD. Engenharia Agrícola, Vol. 37, Iss. 5, 900-906.https://doi.org/10.1590/1809-4430-eng.agric.v37n5p900-906/2017

5. Longui, E. L., Pires, G. T., Ballarin, A. W., Machado, J. A. R. 2017. Shear strength parallel to grain with distinct ray orientation on four Brazilian wood species. European Journal of Wood and Wood Products, Vol. 75, Iss.(4), 663-665. https://doi.org/10.1007/s00107-016-1129-8

6. Mirzaei, B., Sinha, A., Nairn, J.A. 2015.Using crack propagation fracture toughness to characterize the durability of wood and wood composites. Materials \& Design, Vol. 87, pp. 586-592.https://doi.org/10.1016/j.matdes.2015.08.010

7. Peschel, P. 2002. Woodworking manual, Sobotáles nakladatelství

8. Sinha, A., Nairn, J. A., Gupta, R. 2012. The effect of elevated temperature exposure on the fracture toughness of solid wood and structural wood composites. Wood Science and Technology, Vol. 46, Iss. 6, 1127-1149. https://doi.org/10.1007/s00226-012-0473-Z

9. Souček, J., Burg, P., Kroulík, M. 2008. The grapevine waste wood disintegration parameters. AgritechScience, 2. 1-5. available at http://www.vuzt.cz/svt/vuzt/publ/P2008/038.PDF [In Czech].

10. Souček, J., Hanzlíková, I., Hutla, P. 2003. A fine desintegration of plants suitable for composite biofuels production. Research in Agricultural Engineering, Vol. 49, pp. 7-11. 